\title{
Stability analysis for grain yield and some quality traits in bread wheat (Triticum aestivum $\mathbf{L}$.)
}

\author{
Charan Singh ${ }^{1 *}$, Puja Srivastava ${ }^{2}$, Achla Sharma ${ }^{2}$, Pradeep Kumar ${ }^{1}$, Praveen Chhuneja ${ }^{2}$, \\ V.S. Sohu ${ }^{2}$ and N.S. Bains ${ }^{2}$ \\ ${ }^{1}$ Crop Improvement, ICAR-Indian Institute of Wheat and Barley Research, Karnal (Haryana), INDIA \\ ${ }^{2}$ Department of Plant Breeding and Genetics, Punjab Agricultural University, Ludhiana (Punjab), INDIA \\ *Corresponding author. E-mail: n_charansingh@hotmail.com \\ Received: October 30, 2017; Revised received: December 27, 2017; Accepted: February 22, 2018
}

\begin{abstract}
The present study was conducted to assess the genetic diversity and stability for grain yield (GY), 1000grain weight (TGW), protein content (PC), grain iron (Fe) and grain zinc ( $\mathrm{Zn})$ concentration under three varied environmental locations using 28 diverse wheat genotypes (including three checks i.e., WH1105, DPW621-50, and HD2967 ). The material was sown at three locations during Rabi 2015-2016. Pooled analysis of variance revealed highly significant variance due to environments for all the traits studied indicating differential response of the genotypes. The genotype BWL 3584 exhibited stable performance across the environments for grain yield and grain zinc concentration under un-favorable environment also shows potential for high grain yield and high grain zinc concentration. After further confirmation, genotype BWL 3584 could be utilized as potential donor in hybridization programme to improve grain yield and grain zinc concentration. Further, genotype SABW 225 showed consistent performance across the environments for TGW and PC content. Whereas, PBW 744 was found to be suitable for GY $(6142 \mathrm{~kg} / \mathrm{ha})$, coupled with PC $(12.09 \%)$ and Zn $(52.18 \mathrm{ppm})$ across the locations followed by PBW 725 (6094, 12.26 and 46.96) and BWL 3584 (5219, 12.63 and 50.23) GY, PC and Grain Zn, respectively)and BWL 3584 (5219, 12.63 and 50.23 ) could be utilized as a donor in routine breeding programme to improve grain yield and quality traits in bread wheat.
\end{abstract}

Keywords: Bread wheat, Grain yield, Genotype-environment interactions, Multilocation testing, Quality traits

\section{INTRODUCTION}

Grain micronutrients play an important role in plants as well as in human body. Yield and grain protein content are traits of primary importance in wheat breeding programs. The first one is obviously a major determinant of farmer's incomes, while the second one is very important for bread quality (Groos et al., 2003). Prerequisite of breeding programme is to screen and identify phenotypically stable genotype for grain yield, which could perform uniformly under diverse environmental conditions and/or agro-climatic conditions. However, to meet out estimated future demand of wheat production, it is necessary to mitigate challenges such as climate change, depleting natural resources and various type of biotic and abiotic stress etc. Some genotypes frequently show fluctuations in yield performance in different environments as a result of genotype-environment interactions (GxE).Thus, GxE interactions are of major consequence to the breeders in the process of evaluation of improved genotypes when genotypes are grown at multi-locations for testing their performance. However, their relative rankings do not remain the same; this could cause difficulties in demonstrating significant superiority of any genotype. The information about phenotypic stability could be useful for the selection of desirable genotypes for yield and quality traits as well as for breeding programme. Korkut et al. (2007) reported that selection efficiency could be improved by the utilizing stable performing quality traits in crop improvement programme. However, economic instability as defined by the end users is commonly caused by both environment and GxE interaction effects (Letta et al., 2008). Because GxE interaction is expected, the selection of genotypes with superior grain yield required a multi-environment trial (Roozemboom et al., 2008). Genotype evaluation by multi-environment trial has several benefits, including i) the ability to select genotypes that are widely adapted based on the average yield performance in various environments, ii) the ability to select genotypes that are specifically adapted to certain environments i.e., Ludhiana, Bathinda and Gurdaspur, and iii) the ability to identify redundant test locations or environments such that information about wheat genotypes is obtained with minimal duplication (Yan et al., 2010). The manipulation of wheat has led to ever increasing 
gain yield and quality, while decreasing the ability of wheat to survive under varying adverse conditions. The accurate identification of test sites ensures that the selected genotypes show superior performance across several environments (Blanche and Myers, 2006) and improves the efficiency of the breeding programme. A number of techniques have been used to interpret data from multi-environment trials (Eberhart and Russel, 1966), including GGE bi-plot analysis for effectively identifying mega-environments (Munaro et al., 2014). Therefore, we need to have research programme which primarily focus to develop cultivars with high yield potential and consistent performance across the environments. Wheat cultivation under diverse agroclimatic conditions and wide variations in productivity from region to region, crop becomes restricted due to sudden fluctuations in environmental changes. The main objective of a crop breeding programme is to develop varieties that perform well over a broad spectrum of environments. Further, a variety having wide or good adaptability is one which gives consistently superior performance over several environments (Frey, 1964). Thus, the assessment of the nature and extent of GxE interaction and identification of phenotypically stable genotypes, showing low GxE interaction, becomes important. Therefore, the present study was conducted to identify stable wheat genotype and identification and validation of essential test locations in different wheat-growing regions of Punjab, India, which can also be gainfully utilized in future wheat hybridization programme.

\section{MATERIALS AND METHODS}

The material used in the present experiment comprises of twenty five advanced breeding lines in the background of wheat variety DPW621-50, a variety of North West Plains Zone of India along with standard checks. These advanced breeding lines were developed in a two-step process, the first being represented by cross of US hard red spring wheat 'Glupro' with locally adapted spring wheat line PBW 568. This primary round of introgression involved two backcrosses to PBW568. A high grain protein derivative with desirable agronomic features was identified after quality and yield testing of fixed lines for making a cross with DPW621-50. The parentage of these lines used in this study may thus be represented as DPW621-50// Glupro/3*PBW568/3/DPW621-50. Initially a large set of lines were generated in the Wheat Section (BWL and PBW series) and School of Agricultural Biotechnology (SABW series), PAU, Ludhiana. Trials were conducted under high fertility conditions in randomized complete block design with three replications during 2014-15 crop seasons at Ludhiana, Bathinda and Gurdaspur, Punjab. Besides these lines, the trials included three checks represented by recipient parent DPW621-50, WH1105 and HD2967. All the three checks are recommended bread wheat varieties for irrigated, timely sown conditions of North Western Plains Zone of India. Plot size was six rows of 6 meter each with row to row spacing of $20 \mathrm{~cm}$. All the recommended, standard cultural practices were followed to raise the crop.

Grain protein content estimation: Total grain protein content was estimated using "Infratec 1241" grain analyzer supplied by M/S Foss Analytical AB, Sweden. The instrument uses near infra-red light transmitted through the grains. The grain samples were scanned in the range of 850 to $1050 \mathrm{~nm}$ with a bandwidth of $7 \mathrm{~nm}$ and there are 100 data points per scan. The results were displayed as percent protein content and percent moisture in the grain. The final protein value was standardized at $14 \%$ moisture.

Grain zinc and iron concentration estimation: Grain zinc and iron concentration (ppm) were analyzed using "Energy Dispersive X-ray Fluorescence" (EDXRF) which is a non-destructive method used to estimate zinc and iron concentrations in wheat grains. EDXRF was performed using an Oxford Instruments $\mathrm{X}$ Supreme 8000 fitted with a 10 places auto-sampler. Scans were conducted in sample cups assembled from 21 $\mathrm{mm}$ diameter aluminum (Al) cups combined with polypropylene inner cups sealed at one end with $4 \mu \mathrm{m}$ Poly- 4 XRF sample film. Cups containing samples were gently shaken to evenly distribute grains. The X-Supreme 8000 scans a circle of $21 \mathrm{~mm}$ diameter with the sample spinner on. All scans in this study were performed in this mode, so the scanned area was $346 \mathrm{~mm}^{2}$.

Recording of observations, grain sampling and micronutrient analysis: Observations were recorded for 1000 grain weight $(\mathrm{g})$, grain yield per hectare $(\mathrm{kg})$, grain protein content $(\%)$, grain zinc concentration $(\mathrm{ppm})$ and grain iron concentration (ppm). A random sample of 20 spikes per entry was harvested after physiological maturity, the spikes were threshed in a clean cloth and the grain was separated from husk. The grain was sampled for iron and zinc analysis. Care was taken at every step to avoid metal contamination. The grain samples were analyzed at Wheat Quality Laboratory, PAU, Ludhiana, India, using a new cost-effective, high throughput method called Energy Dispersive Xray Fluorescence (EDXRF).

Statistical analysis: The mean values from each replication were subjected to statistical analysis using SAS and CROPSTAT computer software. The analysis of variance was carried out as per Panse and Sukhatme (1985). Stability parameters, were computed as per Eberhart and Russell (1966), Singh and Chaudhary (1985). Estimates of mean performance (x), regression coefficient (bi) and deviations from regression $\left(\mathrm{S}^{2} \mathrm{di}\right)$ were used to draw inferences on stability of genotypes.

\section{RESULTS AND DISCUSSION}

The location-wise analysis of variance (Table 1) was 
Charan Singh et al. / J. Appl. \& Nat. Sci. 10 (1): 466 - 474 (2018)

Table 1. Location wise analysis of variance (ANOVA) for grain yield and quality traits in bread wheat.

\begin{tabular}{|c|c|c|c|c|c|c|}
\hline \multirow[b]{2}{*}{$\begin{array}{l}\text { Source of vari- } \\
\text { ation }\end{array}$} & \multirow[b]{2}{*}{ D F } & \multicolumn{5}{|c|}{ Mean 0sum of square } \\
\hline & & $\begin{array}{l}\text { 1000-grain } \\
\text { weight (g) }\end{array}$ & $\begin{array}{l}\text { Grain yield } \\
\text { (kg/ha) }\end{array}$ & $\begin{array}{l}\text { Protein con- } \\
\text { tent }(\%)\end{array}$ & $\begin{array}{l}\text { Zinc concentration } \\
(\mathrm{ppm})\end{array}$ & $\begin{array}{l}\text { Iron concentration } \\
(\mathrm{ppm})\end{array}$ \\
\hline \multicolumn{7}{|c|}{ Location (Ludhiana) } \\
\hline Replications & 2 & 1.75 & 12.95 & 0.56 & 21.83 & 6.52 \\
\hline Genotypes & 27 & $36.39 * *$ & $1795115.00 * *$ & 0.54 & 54.43 & $17.20^{*}$ \\
\hline Error & 54 & 8.53 & 40051.98 & 0.42 & 71.89 & 9.39 \\
\hline Total & 83 & 17.43 & 610011.31 & 0.47 & 65.01 & 11.87 \\
\hline \multicolumn{7}{|l|}{ B } \\
\hline \multicolumn{7}{|c|}{ Location (Bathinda) } \\
\hline Replications & 2 & 0.46 & 68657.90 & 0.01 & -0.01 & 0.01 \\
\hline Genotypes & 27 & $32.20 * *$ & $1990513.12 * *$ & $0.78 * *$ & $36.18 * *$ & $33.50 * *$ \\
\hline Error & 54 & 1.12 & 43184.75 & 0.03 & 0.00 & -0.00 \\
\hline Total & 83 & 11.21 & 677266.81 & 0.27 & 11.76 & 10.89 \\
\hline \multicolumn{7}{|l|}{ B } \\
\hline \multicolumn{7}{|c|}{ Location (Gurdaspur) } \\
\hline Replications & 2 & 17.77 & 39990.14 & -0.00 & 0.17 & 33.19 \\
\hline Genotypes & 27 & $54.73 * *$ & $2133820.25 * *$ & $0.49 * *$ & $26.86^{* *}$ & $223.08 * *$ \\
\hline Error & 54 & 8.10 & 25562.13 & 0.01 & 0.32 & 15.01 \\
\hline Total & 83 & 23.50 & 711728.75 & 0.16 & 8.95 & 83.13 \\
\hline
\end{tabular}

Table 2. Pooled analysis of variance (ANOVA) for grain yield and quality traits.

\begin{tabular}{lcccccc}
\hline $\begin{array}{l}\text { Source of vari- } \\
\text { ation }\end{array}$ & D F & $\begin{array}{c}\mathbf{1 0 0 0} \\
\text { grain weight }\end{array}$ & $\begin{array}{c}\text { Grain yield } \\
(\mathbf{k g} / \mathbf{h a})\end{array}$ & $\begin{array}{c}\text { Protein } \\
\text { content (\%) }\end{array}$ & $\begin{array}{c}\text { Grain zinc con- } \\
\text { centration (ppm) }\end{array}$ & $\begin{array}{c}\text { Grain iron con- } \\
\text { centration (ppm) }\end{array}$ \\
\hline Genotypes & 27.00 & $25.84^{* *}$ & $1807226.50^{* *}$ & $0.25^{* *}$ & $23.53^{* *}$ & $39.16^{* *}$ \\
E+ (G x E) & 56.00 & 9.72 & $140206.94^{* *}$ & $0.31^{* *}$ & $350.94^{* *}$ & $38.22^{* *}$ \\
Environments & 2.00 & $66.10^{* *}$ & $1685835.25^{* *}$ & $3.92^{* *}$ & $9615.31^{* *}$ & $366.63^{* *}$ \\
G x E & 54.00 & 7.63 & $82961.45^{*}$ & 0.18 & 7.81 & $26.05^{* *}$ \\
Environments & & & & & & \\
(linear) & 1.00 & $132.20^{* *}$ & $3371670.50^{* *}$ & $7.83^{* *}$ & $19230.61^{* *}$ & $733.27^{* *}$ \\
G x E (linear) & 27.00 & 7.43 & $125551.97^{* *}$ & $0.25^{*}$ & $10.23^{*}$ & $47.56^{* *}$ \\
Pooled deviation & 28.00 & $7.56^{* *}$ & $38929.10^{* *}$ & $0.10^{* *}$ & 5.20 & $4.38^{*}$ \\
Pooled error & 162.00 & 1.97 & 12088.76 & 0.05 & 8.02 & 2.71 \\
Total & 83.00 & 14.97 & 682490.44 & 0.29 & 244.43 & 38.52 \\
\hline
\end{tabular}

significant for all the traits in all the locations (Ludhiana, Bathinda and Gurdaspur) except protein content and zinc concentration in Ludhiana location, suggesting sufficient variability in the present set of materials. The pooled analysis of variance concerning all the five traits is presented in (Table 2). The variances due to genotypes were significant for 1000-grain weight, grain yield per hectare, grain protein content, grain zinc concentration and grain iron concentration indicated differential response of the genotypes selected for the present study. The variances due to environment was significant for 1000 grain weight, grain yield (kg) per hectare, grain protein content, grain zinc concentration and grain iron concentration indicated the distinct and differential effects of different environmental conditions. Similar results were also reported by Kumar et al. (2014) for grain yield and thousand grain weight and Gopalareddy et al. (2015) for zinc and iron concentration in wheat. The variance due to genotype $\mathrm{x}$ environment interaction was found significant at 5\% level of significance for grain yield per hectare and grain iron concentration sowing differential response of the varieties with different environments. The similar findings for genotype $\mathrm{x}$ environment interaction for grain yield per hectare, protein content and grain iron concentration were reported by Nagarajan et al. (2007); Gowda et al. (2010); Singh and Tyagi (2014) for grain yield and Gopalareddy et al. (2015) for zinc and iron concentration in wheat. The mean squares due to environment + (genotype $\mathrm{x}$ environment) interaction were significant for grain yield per hectare $(\mathrm{kg})$, grain protein content $(\%)$, grain zinc concentration (ppm) and grain iron concentration which showed that genotypes were interacted considerably with environmental conditions that existed over different locations. Mean sum of squares due to environments (linear) was significant for all traits (1000 grain weight, grain yield per hectare $(\mathrm{kg})$, grain protein content $(\%)$, grain zinc concentration (ppm) and grain iron concentration, but the significant difference indicating that environment effects are additive. The significant linear component of $\mathrm{GxE}$ interaction was also recorded for grain yield per hectare $(\mathrm{kg})$, grain protein content $(\%)$, grain zinc concentration (ppm) and grain iron concentration indicating differential response of the genotypes with in different environments (locations). Hence, it would be possible to predict the performance of genotypes over wide range of environments (multilocation) for these traits. The traits namely 1000 grain weight, grain yield per hectare $(\mathrm{kg})$, grain protein 
Charan Singh et al. / J. Appl. \& Nat. Sci. 10 (1): 466 - 474 (2018)

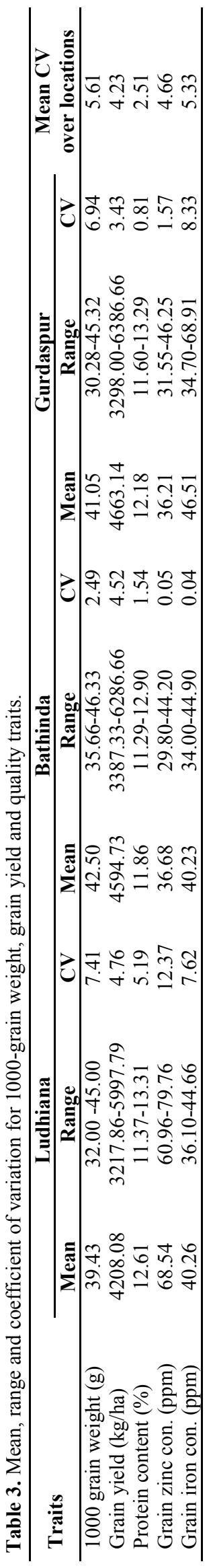

Table 4. Environmental Index for grain yield, 1000-grain weight and quality traits.

\begin{tabular}{llll}
\hline Traits & Ludhiana & Bathinda & Gurdaspur \\
\hline 1000 grain weight $(\mathrm{g})$ & -1.563 & 1.508 & 0.055 \\
Grain yield $(\mathrm{kg} / \mathrm{ha})$ & -280.566 & 106.074 & 174.492 \\
Protein content (\%) & 0.391 & -0.354 & -0.037 \\
$\begin{array}{l}\text { Zinc concentration } \\
\text { (ppm) }\end{array}$ & 21.396 & -10.467 & -10.929 \\
$\begin{array}{l}\text { Iron concentration } \\
(\mathrm{ppm})\end{array}$ & -2.073 & -2.105 & 4.178 \\
\hline
\end{tabular}

content (\%) and grain iron concentration (ppm) were having significant pooled deviation at $5 \%$ level of significance which indicated that some portion of GxE interaction was unpredictable. Similarly, Gowda et al. (2010) and Singh and Tyagi (2014) in wheat was observed significant deviations from regression for grain yield and grain iron concentration ( $\mathrm{ppm}$ ), respectively.

Genetic variability: In the present study, 1000-grain weight ranged from 35.00-45.00g (mean 39.43g) at Ludhiana, 35.66-46.33g (mean 42.50g) at Bathinda and 30.28-45.32g (mean 41.02) at Gurdaspur, whereas pooled mean across the location was $40.99 \mathrm{~g}$. The range for grain yield was $3217.86-5997.79 \mathrm{~kg}(4208.08 \mathrm{~kg})$ at Ludhiana, $3387.33-6286.66 \mathrm{~kg}(4594.73 \mathrm{~kg})$ at Bathinda and 3298-6386.66 (4663.14kg) at Gurdaspur whereas, pooled mean across the location was $4488.65 \mathrm{~kg}$. The range for protein content (\%) was varied from 11.37 to $13.31 \%(12.61 \%)$ at Ludhiana, 11.29 $-12.90 \%(11.86 \%)$ at Bathinda and 11.60 to $13.29 \%$ $(12.18 \%)$ at Gurdaspur whereas, pooled mean across the location was $12.22 \%$. The range for zinc concentration was observed as $60.96-79.76 \mathrm{ppm}(68.54 \mathrm{ppm})$ at Ludhiana, 29.80-44.20ppm (36.68ppm) at Bathinda and $31.55-46.25 \mathrm{ppm}(36.21 \mathrm{ppm})$ at Gurdaspur whereas, pooled mean across the location was $47.14 \mathrm{ppm}$. The range for iron concentration was $36.10-44.66 \mathrm{ppm}$ (40.26ppm) at Ludhiana, 34.00-44.90ppm (40.23ppm) at Bathinda and $34.70-68.91 \mathrm{ppm}(46.51 \mathrm{ppm})$ at Gurdaspur whereas, pooled mean across the location was $42.33 \mathrm{ppm}$.

Stability analysis and identification of stable genotypes over locations: Eberhart and Russell (1966) emphasized the need of considering both linear (bi) and non-linear regression coefficient, i.e. deviation from regression $\left(\mathrm{S}^{2} \mathrm{di}\right.$ ) components of $\mathrm{G} \times \mathrm{E}$ interactions to measure the stability of genotypes. The genotypes with lowest deviation around regression line $\left(\mathrm{S}^{2} \mathrm{di}\right)$ were considered to be stable and vice-versa. Along with above measures, the highest mean performance was also considered as a requirement for identifying high grain yield and stability of genotypes. Thus, in the present investigation three measures, viz. higher mean performance, regression coefficient $(\mathrm{bi}=1)$ and deviation from regression $\left(\mathrm{S}^{2} \mathrm{di}=0\right)$ were used to identify superior and stable genotypes. The stability analysis showed a wide range of adaptation and resilient performance of genotypes. The mean performance and estimates of stability parameters for five traits presented in 
Charan Singh et al. / J. Appl. \& Nat. Sci. 10 (1): 466 - 474 (2018)

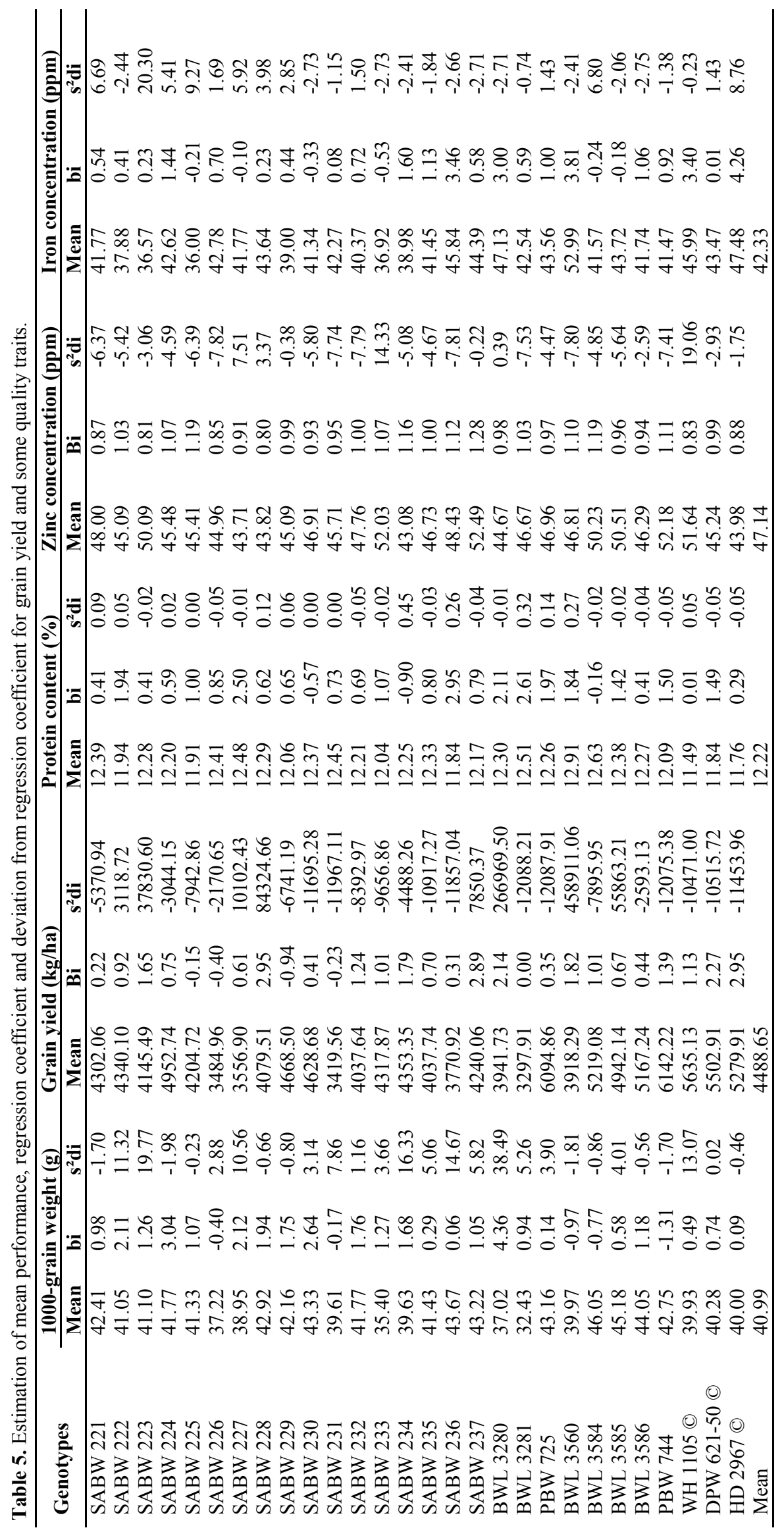


(Table 5). The mean 1000-grain weight ranged from $32.43 \mathrm{~g}-44.05 \mathrm{~g}$ across the locations (environments). Considering high mean performance than population mean and best check with stability parameters together, three genotypes namely SABW 237, SABW 225 and SABW 221 were found desirable and exhibited stable performance across the locations for 1000grains weight. These genotypes give superior performance comparison over the best check for 1000-grain weight. Similar finding was reported by Meena et al. (2014) and Kumar et al. (2014) and also identified some wheat genotypes which give stable performance for 1000-grains weight across the environment. Further, the mean grain yield was ranged from $3297.91 \mathrm{~kg}$ - 6142.22 kg across the locations. Genotype BWL 3584 exhibited stable performance due to their higher mean value than population mean and regression coefficient (b) was very close to unity with non-significant deviations from regression coefficient. The genotypes PBW 744 was having highest mean grain yield over the population mean and also over the best check with regression coefficient greater than unity $(b>1)$. Hence, PBW 744 was observed as well adapted for favorable environmental location. Furthermore, the genotype PBW 725 having higher mean grain yield than population mean and best check and regression coefficient lesser than unity $(b<1)$, hence this genotype are specifically adapted to poor environmental location. The genotype SABW 233 having lower mean grain yield than the population mean than all the three checks with unit regression $(b=1)$, hence, this genotype are poorly adapted to all the environmental locations. Similar findings were also reported by Gowda et al. (2010), Meena et al. (2014), Singh and Tyagi (2014) and Kumar et al. (2014) for stability of genotypes in respect to grain yield across the environments. Similar trends have been reported in other multi-locations or multienvironments field experiments by Yan et al.(2010) and Rakshit et al.(2012). However, the magnitude of environmental effects is irrelevant because the adaptive capacity of a genotype is more important for genotypic selection than specific environmental conditions. The mean protein content was ranged from $11.49 \%$ $12.91 \%$. Among the 28 genotypes, considering high mean performance than population mean and best check with stability parameters together, two genotypes (SABW 225 and SABW 233) exhibited stable performance across the locations, whereas, genotypes SABW 222, SABW 225, SABW 227, BWL 3280, BWL 3281, PBW 725, BWL 3560, BWL 3585 and PBW 744 exhibited stable performance under unfavorable environment for grain protein content. Similarly, for zinc concentration, the mean ranged was 43.0852.49 (ppm) over the locations. Among the 28 genotypes, considering superior mean performance than population mean, regression coefficient near to one with non-significant deviations from regression, the

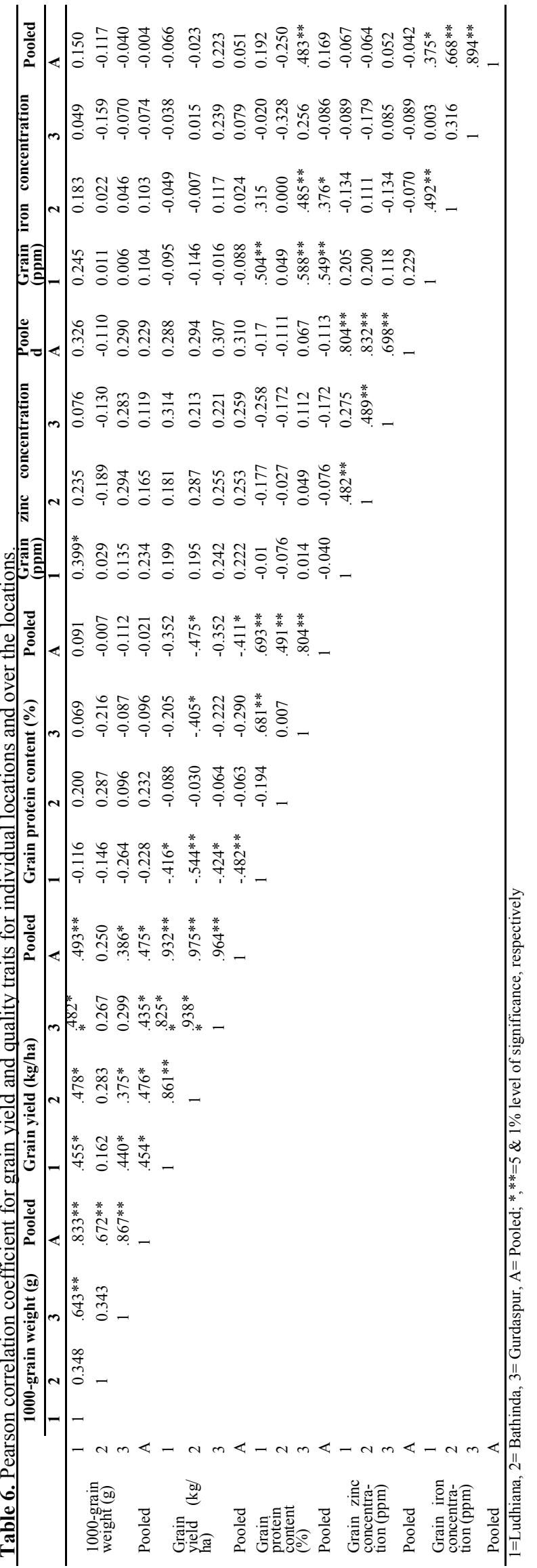


genotype SABW 233 showed stable performance for zinc concentration across the locations. Whereas, the genotypes PBW 744, SABW 237 and BWL 3584, were showed stability under favorable environment allocation for grain zinc concentration due to considering high mean performance with regression coefficient greater than unity $(b>1)$. Similar findings were also reported by Gowda et al. (2010) and Gopalareddy et al. (2015) on stability of genotype for zinc concentration in wheat. The mean for iron concentration was ranged from 36.00-52.99 ppm across the environmental locations. The genotype PBW 725 exhibited stability across the environments due to their higher mean value than population mean and regression coefficient (b) very close to unity with non-significant deviations from regression coefficient whereas, BWL 3560 and SABW 224 were showed stable for favorable environment due to their superior mean performance and regression coefficient (b) more than unity with nonsignificant deviations from regression coefficient for iron concentration (ppm).

The results of the present investigation indicated that none of the genotypes studied were consistently superior for all the traits but some genotypes showed stability for more than one trait. Therefore, on the basis of multi-traits stability of a single genotype we can say that PBW 744 exhibited stable performance for grain yield, protein content and zinc concentration for favorable environment due to their superior mean performance over population mean and best check with regression coefficient (b) more than unity with nonsignificant deviations from regression coefficient. The genotype SABW 233 was observed as stable for across the environmental locations for protein content and zinc concentration (ppm) due to their superior mean performance over best check and regression coefficient (b) was equal to unity with non-significant deviations from regression coefficient. Whereas, BWL 3560 was observed as well adapted under unfavorable environment considering high mean performance and stability parameters for grain protein content and grain iron concentration.

The genotype SABW 225 was specifically adapted across environment for 1000-grain weight and protein content whereas, SABW 237 was well adapted across environment for 1000-grain weight and also well adapted under unfavorable environment for grain zinc concentration based on the high mean performance and stability. The genotype BWL 3584 was stable across environment for grain zinc concentration and well adapted for grain yield under unfavorable environment. Eberhart and Russell (1966), Koemel et al. (2004), Lillimo et al. (2004), Meena et al. (2014) and Kumar et al. (2014) also emphasized that genotypes with high mean performance and regression coefficient near to unity with non-significant deviations are desirable and gave stable performance across the environ- ments. Based on the mean performance, regression coefficient (bi) values and deviation from regression values, some of the genotypes have been identified to suit with stability of performance under unfavorable environments in respect of grain yield and quality traits. In the present study, it seems that the above stable genotypes could be used to develop a new strain with combination of stable traits also reported by Singh and Chaudhary (2007) and Gowda et al. (2010). Larger GxE interaction also complicates the design of an efficient field testing system. An efficient testing system is more important for quality traits than for the agronomic traits (Zhang et al. 2004). However, breeders must keep in mind that the assessments of stability depend on the sets of genotypes and environments studied.

Environmental index: The effect of environment locations (Ludhiana, Bathinda and Gurdaspur), which is taken as indicator for the stability of genotypes and worked out as comparison of mean of the genotypes over the 3 environmental locations for grain yield, 1000-grain weight and some important quality traits by way of environmental index is presented in (Table 4). A perusal of the Table shows for grain yield, the environmental index for Gurdaspur location (174.49) was highest positive which gradually decreased in the Bathinda location (106.07) and negative in Ludhiana (-280.56) location. For 1000-grain weight the values of environmental index was highest with positive value in Bathinda location (1.50) followed by Gurdaspur location (0.05) and negative value in Ludhiana location $(-1.56)$. For quality traits like micronutrients content (Fe \& $\mathrm{Zn}$ ) the value of the environmental index was varied from location to location. For protein content, environmental index showed negative values for Bathinda location (-0.354) and Gurdaspur location (-0.037) whereas, positive values for Ludhiana location (0.39). Zinc concentration showed a negative value $(-10.92)$ for Gurdaspur and (-10.46) for Bathinda whereas, positive value (21.39) for Ludhiana location. For iron concentration environmental index negative value $(-2.07)$ was observed for Ludhiana location and $(-2.10)$ Bathinda whereas, positive value (4.17) for Gurdaspur. These finding were corroborated with the finding of Hailu et al. (2007) and Gowda et al. (2010) in wheat. In conclusion from the above findings we observed that Ludhiana location is ideal for protein content and zinc concentration whereas, Gurdaspur was observed as ideal location for grain yield, protein content and 1000-grain weight. However, the best location for 1000-grain weight was Bathinda location. Gowda et al. (2010) reported similar findings for iron concentration, protein content, zinc concentration and grain yield on the environmental index for different environment (that is normal, late and very late) sowing conditions.

Correlation: Location wise phenotypic correlation 
coefficient for grain yield and quality traits (Table 6) indicated that the 1000-grain weight (TGW) was positively associated with grain yield at three locations i.e., Ludhiana, Bathinda and Gurdaspur ( $\mathrm{r}=0.493^{* *}$, $\left.\mathrm{r}=0.250, \mathrm{r}=0.386^{*}\right)$. It means grain yield at all three locations can be improved by improving the 1000 grain weight in the present set of materials. On the other hand, grain yield for Ludhiana, Bathinda and Gurdaspur was negatively correlated with grain protein content $\left(\mathrm{r}=-0.352^{*}, \mathrm{r}=-475^{*}, \mathrm{r}=-0.352\right)$. Grain yield was positively associated with grain zinc concentration $(\mathrm{r}=0.288, \mathrm{r}=0.294, \mathrm{r}=0.307)$ and negative association was reported with grain iron concentration $(=$ $0.066,0-0.023, \mathrm{r}=-0.223$ ) for Ludhiana, Bathinda and Gurdaspur locations. However, the association observed was not significant (Table 6).

\section{Conclusion}

It can be concluded that SABW 225 showed stable performance for multiple traits namely 1000-grain weight and grain protein content across the environment whereas, PBW 744 was found suitable for unfavorable environment for grain yield, grain protein content and grain zinc concentration. The PBW 744 wheat genotypes with good quality traits may be further assessed for their genetic distance and diverse parent's and could be utilized in future wheat hybridization programme to generate heterotic combinations as well as a donor parents in multiple traits breeding programme to improve grain yield, protein content and zinc concentration in wheat.

\section{REFERENCES}

Blanche and Myers (2006). Identifying discriminating locations for cultivars selection in Louisiana. Crop Science, 46: 946-49.

Eberhart, S.A. and Russell, R.A. (1966). Stability parameters for comparing varieties. Crop Science, 6:36-40.

Frey, (1964). Adaptation reaction of oat strains selected under stress and non-stress environmental conditions. Crop Science, 4: 55-58.

Gopalareddy, K., Singh, A.M, Ahlawat, A.K, Singh, G.P. and Jaiswal, JP. (2015). Genotype-environment interaction for grain iron and zinc concentration in recombinant inbred lines of a bread wheat (Triticum aestivum L.) cross. Indian Journal of Genetics and Plant Breeding, 75(3): 307-13.

Gowda, D., Singh, S.S., Singh, G.P., Deveshwar, A.M., and Ahlawat, A. (2010). Stability analysis for physiological and quality parameters in wheat (Triticum aestivum). Indian Journal of Agricultural Sciences, 80(12):102832

Groos, C., Robert, N., Bervas, E. and Charmet, G. (2003). Genetic analysis of grain protein-content, grain yield and thousand-kernel weight in bread wheat. Theoretical and Applied Genetics, 106(6): 1032-40.

Hailu, J.K., Sarial, A.K. and Assefa, S. (2007). AMMI analysis for stability and location effects of grain protein content of durum wheat genotypes. Cereal Research
Communication, 35: 1661-73.

Koemel, J.E., Guenzi, A.C., Carver, B.F., Payton, M.E., Morgan, G.H. and Smith, E.L. (2004).Hybrids and pureline hard winter wheat yield and stability. Crop Science, 44: 107-13.

Korkut, K.Z., Bilgin, O., Baser, I. and Saolam, N. (2007). Stability of grain virtuousness in durum wheat genotypes in north western region of Turkey. Turkish Journal of Agricultural Forestry, 31: 313-8.

Kumar, V., Tyagi, B.S., Verma, A. and Sharma, I. (2014). Stability analysis for grain yield and its components under different moisture regimes in bread wheat (Triticum aestivum). Indian Journal of Agricultural Sciences, 84(8): 931-6.

Letta, T., Egidio, M.G.D. and Abinasa, M. (2008).Stability analysis for quality traits in durum wheat (Triticum $d u$ rum Desf) varieties under south Eastern Ethiopian conditions.World Journal of Agricultural Sciences, 4(1):537

Lillimo, M., Ginkel, M., Trethowan, R.M., Hernandez, E. and Rajaram, S. (2004). Associations among international CIMMYT bread wheat yield testing locations in high rainfall areas and their implications for wheat breeding. Crop Science, 44: 1163-9.

Meena, H.S., Kumar. D, Srivastava, T.K. and Rajendra, P.S. (2014). Stability for grain yield and its contributing traits in bread wheat (Triticum aestivum). Indian Journal of Agricultural Sciences, 84(12): 1486-95.

Munaro, L.M., Benin, G., Marchioro, V.S., Franco, F.A., Silva, R.R., Silva, C.L., Beche (2014). Brazilian spring wheat homogeneous adaptation regions can be dissected in major mega environments. Crop Science, 54: 137483.

Nagarajan, S., Tripathi, S., Singh, G.P. and Chaudhary, H.B. 2007. Effect of cultivar and environment on quality characteristics of wheat (Triticum aestivum L.). Indian Journal of Genetics and Plant breeding, 67 (2): 149-52.

Panse, V.C. and Sukhatme, P.V. (1985). Statistical Methods for Agricultural Workers. Indian Council of Agricultural Research, New Delhi.

Rakshit, S., Ganapathy, K.N., Gomashe, S.S., Swapna, M., More, A., Gadakh, S.R., Ghorade, R.B., Kajjidoni, S.T., Solanki, B.G., Biradar, B.D., Prabhakar (2014). GGE biplot analysis of genotype $\times$ environment interaction in rabi grain sorghum [Sorghum bicolor (L.) Moench]. Indian Journal of Genetics and plant breeding, 74(4): $558-63$.

Roozemboom, K.L., Schapaugh, W.T., Tuinstra, M.R., Vanderlip, R.L., Miliken, G.A. (2008). Testing wheat in variable environments: genotype, environment, interaction effects and grouping test locations. Crop Science, 48: $317-30$

Singh, G.P. and Chaudhary, H.B. (2007).Stability of wheat genotypes for yield and moisture stress tolerance traits under diverse moisture regimes. Indian Journal of $\mathrm{Ge}$ netics and Plant Breeding, 67(2): 145-8.

Singh, R.K. and Chaudhary, B.D. (1985). Biometrical Methods in Quantitative Genetics Analysis, p 318.Kalyani Publishers, Ludhiana.

Singh, T. and Tyagi, J.P. (2014). Stability for Yield and its Component Traits in Durum Wheat (Triticum durum Desf.). Indian Journal of Plant Genetic Resources, 27 (3): 287-94. 
Charan Singh et al. / J. Appl. \& Nat. Sci. 10 (1): 466 - 474 (2018)

Yan, W., Fregeau-Reid, J., Pageau, D., Martin, R., MitchellFetch, J., Etienne, M., Rowsell, J., Scoot, P., Price, M., Haan, B., Cummiskey -Alajeunesse, J., Durand, J., Sparry, E. (2010). Identifying essential test locations for oat breeding in eastern Canada. Crop Science, 60: 504-515
Zhang-Yong, He-Zhonghu, Guoyou-Ye, Zhang-Aimin and Marten Van Ginkel. (2004). Effect of environment and genotype on breadmaking quality of spring wheat cultivars in China. Euphytica, 139: 75-83 